\title{
Pharmacokinetics and dialytic clearance of apixaban during in vitro continuous renal replacement therapy
}

\author{
Lauren Andrews, Scott Benken, Xing Tan and Eric Wenzler *i)
}

\begin{abstract}
Background: To evaluate the transmembrane clearance $\left(\mathrm{CL}_{T M}\right)$ of apixaban during modeled in vitro continuous renal replacement therapy (CRRT), assess protein binding and circuit adsorption, and provide initial dosing recommendations.
\end{abstract}

Methods: Apixaban was added to the CRRT circuit and serial pre-filter bovine blood samples were collected along with post-filter blood and effluent samples. All experiments were performed in duplicate using continuous venovenous hemofiltration $(\mathrm{CWH})$ and hemodialysis (CWHD) modes, with varying filter types, flow rates, and point of $\mathrm{CWH}$ replacement fluid dilution. Concentrations of apixaban and urea were quantified via liquid chromatographytandem mass spectrometry. Plasma pharmacokinetic parameters for apixaban were estimated via noncompartmental analysis. $\mathrm{CL}_{\mathrm{TM}}$ was calculated via the estimated area under the curve (AUC) and by the product of the sieving/saturation coefficient (SC/SA) and flow rate. Two and three-way analysis of variance (ANOVA) models were built to assess the effects of mode, filter type, flow rate, and point of dilution on $\mathrm{CL}_{\mathrm{TM}}$ by each method. Optimal doses were suggested by matching the AUC observed in vitro to the systemic exposure demonstrated in Phase 2/3 studies of apixaban. Linear regression was utilized to provide dosing estimations for flow rates from 0.5$5 \mathrm{~L} / \mathrm{h}$.

Results: Mean adsorption to the HF1400 and M150 filters differed significantly at 38 and 13\%, respectively, while mean ( \pm standard deviation, SD) percent protein binding was $70.81 \pm 0.01 \%$. Effect of $\mathrm{CWH}$ point of dilution did not differ across filter types, although $\mathrm{CL}_{\mathrm{TM}}$ was consistently significantly higher during CRRT with the HF1400 filter compared to the M150. The three-way ANOVA demonstrated improved fit when $\mathrm{CL}_{T M}$ values calculated by AUC were used (adjusted $R^{2} 0.87$ vs. 0.52), and therefore, these values were used to generate optimal dosing recommendations. Linear regression revealed significant effects of filter type and flow rate on $\mathrm{CL}_{T M}$ by AUC, suggesting doses of $2.5-7.5 \mathrm{mg}$ twice daily (BID) may be needed for flow rates ranging from $0.5-5 \mathrm{~L} / \mathrm{h}$, respectively.

Conclusion: For CRRT flow rates most commonly employed in clinical practice, the standard labeled $5 \mathrm{mg}$ BID dose of apixaban is predicted to achieve target systemic exposure thresholds. The safety and efficacy of these proposed dosing regimens warrants further investigation in clinical studies.

Keywords: Apixaban, Pharmacokinetics, Dialysis, Renal replacement therapy, Sieving coefficient, Saturation coefficient, Transmembrane clearance, CRRT, CWH, CWHD

\footnotetext{
*Correspondence: wenzler@uic.edu

College of Pharmacy, University of Illinois at Chicago, 833 South Wood

Street, Room 164 (M/C 886) "Chicago, IL 60612, USA
}

(c) The Author(s). 2021 Open Access This article is licensed under a Creative Commons Attribution 4.0 International License, which permits use, sharing, adaptation, distribution and reproduction in any medium or format, as long as you give appropriate credit to the original author(s) and the source, provide a link to the Creative Commons licence, and indicate if changes were made. The images or other third party material in this article are included in the article's Creative Commons licence, unless indicated otherwise in a credit line to the material. If material is not included in the article's Creative Commons licence and your intended use is not permitted by statutory regulation or exceeds the permitted use, you will need to obtain permission directly from the copyright holder. To view a copy of this licence, visit http://creativecommons.org/licenses/by/4.0/. The Creative Commons Public Domain Dedication waiver (http://creativecommons.org/publicdomain/zero/1.0/) applies to the data made available in this article, unless otherwise stated in a credit line to the data. 


\section{Background}

Venous thromboembolism (VTE) and new-onset atrial fibrillation (NOAF) occur in up to 37 and $46 \%$ of critically ill patients, respectively, and are responsible for significant morbidity and mortality in the intensive care unit (ICU) [1-7]. Parenteral anticoagulation with unfractionated heparin (UFH) is the current mainstay therapy for VTE and NOAF in this population given its rapid onset of action and short half-life [8]. Due to the potential for serious adverse effects with UFH, activated thromboplastin time (aPTT) monitoring and dose titration are required to maintain exposures within a narrow therapeutic index [9]. Despite the assistance of dosing algorithms and decades of clinical experience, $>75 \%$ of hospitalized patients fail to achieve aPTTs within goal range during the first $24-48 \mathrm{~h}$ after UFH initiation and only $29 \%$ are able to sustain them [10-12]. In the critically ill ICU population, only approximately $50 \%$ of patients achieve therapeutic aPTTs within this same time frame, largely secondary to pathophysiologic and pharmacokinetic (PK) derangements such as sepsis-induced acute kidney injury (AKI), which can necessitate renal replacement therapy (RRT) in up to $70 \%$ of patients [13-21]. Alternatively, despite minimal PK alterations, low molecular weight heparin (LMWH) has demonstrated detrimental pharmacodynamic (PD) properties, including increased thrombin generation time and an increased risk of bleeding in patients receiving RRT [2225]. Given the challenges in optimizing the use of UFH and LMWH in the ICU setting, more reliable anticoagulation therapies are desperately needed for managing critically ill patients, especially those requiring extracorporeal organ support such as continuous RRT (CRRT).

Apixaban, a direct-acting oral anticoagulant (DOAC) agent, has emerged as a potential alternative therapy for the treatment of VTE and NOAF over UFH and LMWH in the ICU population due to its more reliable doseexposure-response relationship, lack of required monitoring, decreased drug-drug interactions, and improved safety profile [8, 26-31]. Pharmacokinetic studies in otherwise healthy subjects with end stage renal disease (ESRD) on intermittent hemodialysis (HD) indicate that HD has a limited overall impact on the clearance (CL) of apixaban [32-35]. However, data regarding CL by conventional $\mathrm{HD}$ cannot be accurately extrapolated to CRRT given the differences in modes, durations of therapy, types of hemofilters used, and blood, ultrafiltration, and dialysate flow rates [36]. Unfortunately, robust PK data in patients receiving CRRT are scarce and often include only small numbers of critically ill patients on many different forms of CRRT with heterogeneous flow rates, filter types, dosing, and sampling schemes, making it difficult to draw meaningful conclusions [37-41]. As such, in vitro CRRT models are useful for generating precise assessments of sieving/saturation coefficients (SC/SA) across different modes, flow rates, filter types, and points of dilution while eliminating the variability introduced by the patient. As recognized by the U. S Food and Drug Administration (FDA), National Institutes of Health $(\mathrm{NIH})$, and National Institute of Allergy and Infectious Diseases (NIAID), these models can be used to guide dosing in the absence of, or when combined with, in vivo data and have been shown to accurately predict in vivo total body clearance $\left(\mathrm{CL}_{\mathrm{T}}\right)$ [42], allowing for data derived from in vitro investigations to be utilized in estimating clinical dosing regimens [43].

Although apixaban may represent a safer and more efficacious alternative to UFH and LMWH in ICU patients, the lack of PK data to inform appropriate dosing in patients undergoing CRRT currently precludes its use in a significant proportion of the critically ill population. As such, the objective of this study was to evaluate the PK and dialytic clearance of apixaban during in vitro CRRT in order to provide initial guidance on optimal dosing in this population.

\section{Methods \\ Study design \\ In vitro CRRT clearance model}

In vitro CRRT was simulated using a Prismaflex 7.2 control unit (Baxter Healthcare Corporation, Deerfield, IL, USA) in continuous veno-venous hemofiltration $(\mathrm{CVVH})$ and continuous veno-venous hemodialysis (CVVHD) modes using fresh $1.4 \mathrm{~m}^{2}$ polyarylethersulfone (PAES; Prismaflex HF1400) and $1.5 \mathrm{~m}^{2}$ acrylonitrile (AN69; Prismaflex M150) hemofilter sets for each experiment. One liter of heparinized $(20$ units $/ \mathrm{mL})$ whole bovine blood (Densco Marketing Inc., Woodstock, IL, USA) was heated to $37^{\circ} \mathrm{C}$ in a water bath and stirred continuously. The Prismaflex circuit was initially primed with $186 \mathrm{~mL}$ (HF1400) or $189 \mathrm{~mL}$ (M150) of $0.9 \%$ sodium chloride per the manufacturer's operating instructions [44, 45]. Prior to the start of each experiment, blood was then allowed to circulate throughout the system for at least $2 \mathrm{~min}$ to permit adequate exposure of the hemofilter to blood proteins. The blood flow rate was fixed at $200 \mathrm{~mL} / \mathrm{min}$ for all experiments while CVVH replacement fluid (PrismaSOL ${ }^{\circ}$ BGK 2/0; Baxter Healthcare Corporation, Deerfield, IL, USA) and CVVH D dialysate (PrismaSATE ${ }^{\oplus}$ BGK 2/0; Baxter Healthcare Corporation, Deerfield, IL, USA) rates of $2 \mathrm{~L} / \mathrm{h}$ and $4 \mathrm{~L} / \mathrm{h}$ were tested with each filter type. During CVVH at $2 \mathrm{~L} / \mathrm{h}$, replacement fluid was added $100 \%$ pre-filter, $100 \%$ postfilter, and at $50 \%$ pre- $150 \%$ post-filter. During $\mathrm{CVVH}$ at $4 \mathrm{~L} / \mathrm{h}$, replacement fluid was added at $50 \%$ pre- $/ 50 \%$ post-filter. All experiments were performed in duplicate in each mode, at each rate, and with each filter for a 
total of 24 experiments (excluding adsorption experiments).

Apixaban (Eliquis; ${ }^{\oplus}$ Bristol-Myers Squibb, New York, NY, USA) was reconstituted per manufacturer's instructions [46]. To account for measured bovine hematocrit of $36.9 \%$ (Biologic Resources Laboratory, University of Illinois at Chicago, Chicago, IL, USA), the dose of apixaban added to the central reservoir was adjusted a priori to simulate the mean peak serum concentration observed in healthy adult subjects following a single $5 \mathrm{mg}$ dose of apixaban $(\sim 0.104 \mathrm{mg} / \mathrm{L})$ [47]. Urea (Sigma-Aldrich, St. Louis, MO, USA) was also added at $75 \mathrm{mg} / \mathrm{L}$ to serve as the control solute.

After at least $1 \mathrm{~min}$ of equilibration, serial pre-filter blood samples were collected in 3.2\% sodium citrate tubes (Becton, Dickinson and Company, Franklin Lakes, NJ, USA) at 0, 10, 20, 30, 45, and 60 min post-dose with analogous post-filter blood and effluent samples collected at 10 and $30 \mathrm{~min}$. Blood samples were centrifuged at $1500 \times \mathrm{g}$ for $10 \mathrm{~min}$ and the resultant supernatant plasma and ultrafiltrate samples were frozen at $-80^{\circ} \mathrm{C}$ within 30 min of collection until analysis.

\section{Adsorption experiments}

To evaluate potential adsorption of apixaban to the hemofilters, the initial CRRT model was modified to create a closed-circuit system. Effluent was rerouted to the central blood reservoir, and $0.9 \%$ normal saline was exogenously pumped into the effluent bag via a Masterflex ${ }^{\odot}$ Peristaltic pump (Cole-Parmer, Vernon Hills, IL, USA) at the same rate to prevent the Prismaflex system from aborting due to the patient blood loss/gain alarm. Serial blood samples were drawn from the central reservoir at $0,10,20,30,45,60,90,105,120,150$, and $180 \mathrm{~min}$, centrifuged at $1500 \times \mathrm{g}$ for $10 \mathrm{~min}$, and supernatant plasma was frozen at $-80{ }^{\circ} \mathrm{C}$ within $30 \mathrm{~min}$ of collection until analysis. This process was repeated twice in duplicate for a total of 4 experiments.

\section{Protein binding determination}

To assess apixaban protein binding in bovine plasma, 4 contrived samples were centrifuged at $2000 \times \mathrm{x}$ for 30 min using a Centrifree Ultrafiltration Device (Merck Millipore Ltd. Tullagreen, Carrigtwohill, Co. Cork, Ireland) with resulting bound and unbound plasma samples frozen at $-80{ }^{\circ} \mathrm{C}$ within $30 \mathrm{~min}$ until analysis. This process was repeated twice in duplicate for a total of 4 experiments.

\section{Bioanalytical procedures}

Concentrations of apixaban and urea in bovine plasma and effluent were quantified via liquid chromatographytandem mass spectrometry (Keystone Bioanalytical, North Wales, PA, USA) as previously described [48].
The calibration range of the assay was linear from $0.001-0.2 \mathrm{mg} / \mathrm{L}(r \geq 0.999)$. The precision and accuracy acceptance criteria for the quality control (QC) samples and calibration standards were $\leq 15 \%$ coefficient of variance $(\mathrm{CV})$ and $\pm 15 \%$ relative error (RE) determined at each concentration level.

\section{Pharmacokinetic procedures}

Pharmacokinetic parameters for apixaban were estimated from observed pre-filter plasma concentrations via noncompartmental analysis in Phoenix WinNonlin Version 8.1 (Certara USA Inc., Princeton, NJ, USA). Reported parameters included: maximum plasma concentration $\left(\mathrm{C}_{\max }\right)$, last observed plasma concentration $\left(C_{\text {last }}\right)$, elimination rate constant $\left(K_{e}\right)$, half-life $\left(t_{1 / 2}\right)$, apparent volume of distribution $\left(\mathrm{V}_{\mathrm{d}}\right)$, clearance $(\mathrm{CL})$, and the area under the concentration-time curve $\left(\mathrm{AUC}_{0-\infty}\right.$ and $\left.\mathrm{AUC}_{0 \text {-last }}\right)$ as determined via the linear up-log down method. As in vitro experiments were performed over a period of one hour, $\mathrm{AUC}_{0 \text {-last }}$ was multiplied by 24 to demonstrate proportional $\mathrm{AUC}_{0-24}$. Calculations for the estimation of apixaban and urea removal from the CRRT circuit were as follows:

$$
\begin{aligned}
& \text { sieving coefficient }(\mathrm{SC})=\left(\mathrm{C}_{\mathrm{uf}} / \mathrm{C}_{\mathrm{pre}}\right) \\
& \text { saturation coefficient }(\mathrm{SA})=\left(2 * \mathrm{C}_{\text {dialysate }}\right) /\left(\mathrm{C}_{\text {pre }}+\mathrm{C}_{\mathrm{post}}\right)
\end{aligned}
$$

Where $C_{u f}$ is the concentration in the ultrafiltrate, $C_{p r e}$ is the concentration from the pre-filter sampling port, $\mathrm{C}_{\text {dialysate }}$ is the concentration in the dialysate, and $\mathrm{C}_{\text {post }}$ is the concentration from the post-filter sampling port [49-51].

Clearance by CRRT was then estimated by two distinct methods to ensure accuracy and allow for comparison. The primary method of estimating $\mathrm{CL}_{\mathrm{TM}}$ was estimated using the $\mathrm{AUC}_{0-24}$ determined via noncompartmental analysis $\left(\mathrm{CL}_{\mathrm{TM}}\right.$ by $\left.\mathrm{AUC}\right)$, as previously described. The secondary method, $\mathrm{CL}_{\mathrm{TM}}$ by sieving/ saturation coefficients (SC/SA), utilized the following equations:

$$
\begin{aligned}
& \mathrm{CL}_{\mathrm{CVVH}}=\left(\mathrm{SC} * \mathrm{Q}_{\mathrm{uf}} * \mathrm{Q}_{\mathrm{b}}\right) /\left(\mathrm{Q}_{\mathrm{b}}+\mathrm{Q}_{\mathrm{rep}}\right) \\
& \mathrm{CL}_{\mathrm{CVVHD}}=\left(\mathrm{SA} * \mathrm{Q}_{\mathrm{d}}\right)
\end{aligned}
$$

Where $\mathrm{Q}_{\mathrm{uf}}$ is the ultrafiltrate or replacement fluid flow rate and $\mathrm{Q}_{\mathrm{d}}$ is the dialysate flow rate. In experiments where replacement fluid was added pre-filter, a dilutional correction factor was incorporated into the clearance equation, with $\mathrm{Q}_{\mathrm{b}}$ representing blood flow rate and $Q_{\text {rep }}$ being the pre-filter replacement fluid rate $[51,52]$.

Adsorption was calculated as the difference between the total amount of apixaban added to the system and the total amount recovered in the dialysate and plasma after $180 \mathrm{~min}$ using the following equation at each sampling time point [53]: 
Adsorption $(\%)=\Sigma 1-[$ (dose of apixaban added at time zero $)$ /(concentration ofapixaban $*$ measured volume in central reservoir)]

\section{Optimal dosing determination}

Optimal dosing was calculated to provide a comparable mean AUC value to that achieved following the administration of apixaban $5 \mathrm{mg}$ twice daily for 7 days in healthy subjects $(2103.8 \mathrm{mg} \cdot \mathrm{h} / \mathrm{L})$ via the equation $\mathrm{AUC}=$ Dose / $\mathrm{CL}_{\mathrm{T}}$; where $\mathrm{CL}_{\mathrm{T}}=\mathrm{CL}_{\mathrm{TM}}+\mathrm{CL}_{\mathrm{NR}}$ [54]. Here, $\mathrm{CL}_{\mathrm{T}}$ represents total body clearance, $\mathrm{CL}_{\mathrm{TM}}$ represents $\mathrm{CL}$ via CRRT, and $C L_{N R}$ is non-renal clearance. The value for $\mathrm{CL}_{\mathrm{NR}}(2.52 \mathrm{~L} / \mathrm{h})$ was imputed from Phase 2 and 3 studies evaluating apixaban for the treatment or prevention of recurrent VTE and assumed to be constant $[55,56]$. Additionally, residual renal function was assumed to be negligible as the majority of critically ill patients with AKI on CRRT have no appreciable residual renal function [52].

\section{Statistical analysis}

Data are presented as mean ( \pm standard deviation, SD) or with $95 \%$ confidence intervals $(95 \% \mathrm{CI})$. Continuous data were compared via Student's t-test. Additionally, one- and two-way analysois of variance (ANOVA) models with Tukey's post-hoc tests were built to evaluate statistically significant differences in mean $\mathrm{CL}_{\mathrm{TM}}$ according to CVVH point of dilution within and between each filter type, respectively. Then, three-way ANOVA models were fit using $\mathrm{CL}_{\mathrm{TM}}$ as the outcome to evaluate the interaction between CRRT mode, filter type, and flow rate. ANOVA-generated means and 95\% CI of $\mathrm{CL}_{\mathrm{TM}}$ were then used to estimate AUC and optimal total daily doses (TDD) of apixaban during CRRT. Finally, multiple linear regression via backwards stepwise analysis was used to correlate flow rate with mean $\mathrm{CL}_{\mathrm{TM}}$ while adjusting for covariates (CRRT mode, filter type, point of dilution, and flow rate) and predict optimal dosing regimens across flow rates from $0.5-5 \mathrm{~L} / \mathrm{h}$. Model performance was assessed via the adjusted $R^{2}$ value. Collinearity was assessed via tolerance and variance inflation factor. A $P$ value of $\leq 0.05$ was considered statistically significant in the final model. All statistical analyses were performed using SPSS ${ }^{\odot}$ Version 26 (IBM Corp, Armonk, NY, USA).

\section{Results}

\section{In vitro CRRT clearance model}

Mean $( \pm \mathrm{SD})$ pre-filter PK parameters of apixaban in bovine plasma during CRRT as estimated via noncompartmental analyses are summarized in Table 1, and respective plasma concentration-time profiles are shown in Fig. 1. The mean $( \pm S D) C_{\max }$ value observed across the 24 experiments was $0.106 \pm 0.014 \mathrm{mg} / \mathrm{L}(<2 \%$ difference from target value of $0.104 \mathrm{mg} / \mathrm{L})$. Notably, $\mathrm{CL}_{\mathrm{TM}}$ by AUC did not scale proportionally with flow rate, with increases in $\mathrm{CL}_{\mathrm{TM}}$ ranging from 1.3-1.8-fold as flow rate increased from 2 to $4 \mathrm{~L} / \mathrm{h}$.

Table 1 Bovine plasma pharmacokinetic parameters of apixaban during in vitro CRRT as determined via noncompartmental analyses $^{\mathrm{a}}$

\begin{tabular}{|c|c|c|c|c|c|c|c|c|c|}
\hline & $C_{\max }(\mathrm{ng} / \mathrm{mL})$ & $\mathrm{C}_{\text {last }}(\mathrm{ng} / \mathrm{mL})$ & $\mathrm{K}_{\mathrm{e}}\left(\mathrm{hr}^{-1}\right)$ & $t_{1 / 2}(\mathrm{~h})$ & $V_{d}(L)$ & $\mathrm{CL}_{\mathrm{TM}}(\mathrm{L} / \mathrm{h})$ & $\begin{array}{l}\text { AUC }_{0-\infty} \\
(\mathrm{ng} \cdot \mathrm{h} / \mathrm{mL})\end{array}$ & $\begin{array}{l}\text { AUC }_{0 \text {-last }} \\
(\mathrm{ng} \cdot \mathrm{h} / \mathrm{mL})\end{array}$ & $\begin{array}{l}\text { AUC }_{0-24} \\
(\mathrm{ng} \cdot \mathrm{h} / \mathrm{mL})\end{array}$ \\
\hline $\mathrm{CWH}$ & & & & & HF1400 & & & & \\
\hline $2 \mathrm{~L} / \mathrm{h}, 50 / 50 \%$ & $106.5 \pm 0.7$ & $23.4 \pm 1.6$ & $0.9 \pm 0.0$ & $0.8 \pm 0.0$ & $2.2 \pm 0.0$ & $1.9 \pm 0.1$ & $66.8 \pm 2.7$ & $39.3 \pm 0.2$ & $943.6 \pm 4.9$ \\
\hline $2 \mathrm{~L} / \mathrm{h}, 100 / 0 \%$ & $113.3 \pm 21.2$ & $21.2 \pm 4.5$ & $0.9 \pm 0.2$ & $0.8 \pm 0.2$ & $2.0 \pm 0.0$ & $1.7 \pm 0.4$ & $78.2 \pm 18.5$ & $44.5 \pm 5.0$ & $1068.9 \pm 120.5$ \\
\hline 2 L/h, 0/100\% & $108.5 \pm 3.2$ & $24.3 \pm 2.0$ & $1.0 \pm 0.2$ & $0.7 \pm 0.2$ & $1.9 \pm 0.2$ & $1.9 \pm 0.2$ & $66.9 \pm 7.2$ & $42.1 \pm 0.3$ & $1009.8 \pm 6.8$ \\
\hline $4 \mathrm{~L} / \mathrm{h}, 50 / 50 \%$ & $86.5 \pm 4.5$ & $13.1 \pm 1.2$ & $1.3 \pm 0.1$ & $0.5 \pm 0.0$ & $2.6 \pm 0.4$ & $3.3 \pm 0.3$ & $38.2 \pm 3.4$ & $27.9 \pm 3.1$ & $669.4 \pm 73.5$ \\
\hline \multicolumn{10}{|l|}{ CWHD } \\
\hline $2 \mathrm{~L} / \mathrm{h}$ & $117.7 \pm 1.9$ & $26.9 \pm 1.8$ & $0.9 \pm 0.1$ & $0.8 \pm 0.1$ & $1.9 \pm 0.0$ & $1.7 \pm 0.2$ & $75.7 \pm 8.1$ & $44.1 \pm 2.2$ & $1058.0 \pm 52.2$ \\
\hline $4 \mathrm{~L} / \mathrm{h}$ & $119.1 \pm 7.4$ & $20.5 \pm 1.6$ & $1.2 \pm 0.2$ & $0.6 \pm 0.1$ & $1.9 \pm 0.2$ & $2.2 \pm 0.1$ & $58.1 \pm 3.5$ & $40.1 \pm 0.4$ & $962.7 \pm 9.7$ \\
\hline $\mathrm{CWH}$ & & & & & M150 & & & & \\
\hline $2 \mathrm{~L} / \mathrm{h}, 50 / 50 \%$ & $107.9 \pm 16.2$ & $31.0 \pm 10.2$ & $0.9 \pm 0.3$ & $0.9 \pm 0.3$ & $1.8 \pm 0.4$ & $1.6 \pm 0.7$ & $92.5 \pm 37.0$ & $49.6 \pm 11.8$ & $1191.0 \pm 283.3$ \\
\hline $2 \mathrm{~L} / \mathrm{h}, 100 / 0 \%$ & $90.4 \pm 13.8$ & $34.3 \pm 9.9$ & $0.7 \pm 0.3$ & $0.9 \pm 0.2$ & $1.8 \pm 0.3$ & $1.3 \pm 0.6$ & $97.1 \pm 25.6$ & $50.6 \pm 10.8$ & $1214.3 \pm 259.3$ \\
\hline $2 \mathrm{~L} / \mathrm{h}, 0 / 100 \%$ & $108.4 \pm 13.3$ & $40.3 \pm 9.5$ & $0.7 \pm 0.3$ & $1.0 \pm 0.2$ & $1.5 \pm 0.3$ & $1.1 \pm 0.6$ & $117.6 \pm 28.6$ & $60.8 \pm 10.7$ & $1458.6 \pm 256.9$ \\
\hline $4 \mathrm{~L} / \mathrm{h}, 50 / 50 \%$ & $94.9 \pm 15.1$ & $23.2 \pm 9.9$ & $1.2 \pm 0.3$ & $0.6 \pm 0.2$ & $1.7 \pm 0.4$ & $2.1 \pm 0.7$ & $62.2 \pm 29.9$ & $42.1 \pm 11.8$ & $1009.3 \pm 283.1$ \\
\hline \multicolumn{10}{|l|}{ CWHD } \\
\hline $2 \mathrm{~L} / \mathrm{h}$ & $117.3 \pm 14.2$ & $46.2 \pm 10.4$ & $0.7 \pm 0.2$ & $1.1 \pm 0.2$ & $1.4 \pm 0.4$ & $0.9 \pm 0.7$ & $139.2 \pm 32.6$ & $69.0 \pm 12.8$ & $1656.1 \pm 307.5$ \\
\hline $4 \mathrm{~L} / \mathrm{h}$ & $121.4 \pm 14.3$ & $26.9 \pm 9.7$ & $1.3 \pm 0.3$ & $0.5 \pm 0.2$ & $1.3 \pm 0.3$ & $1.6 \pm 0.6$ & $77.2 \pm 29.3$ & $56.1 \pm 11.2$ & $1346.3 \pm 269.0$ \\
\hline
\end{tabular}

Data are presented as mean \pm SD

${ }^{a} n=2$ experiments in each mode, at each flow rate, point of dilution, and filter type ( 24 total experiments) 

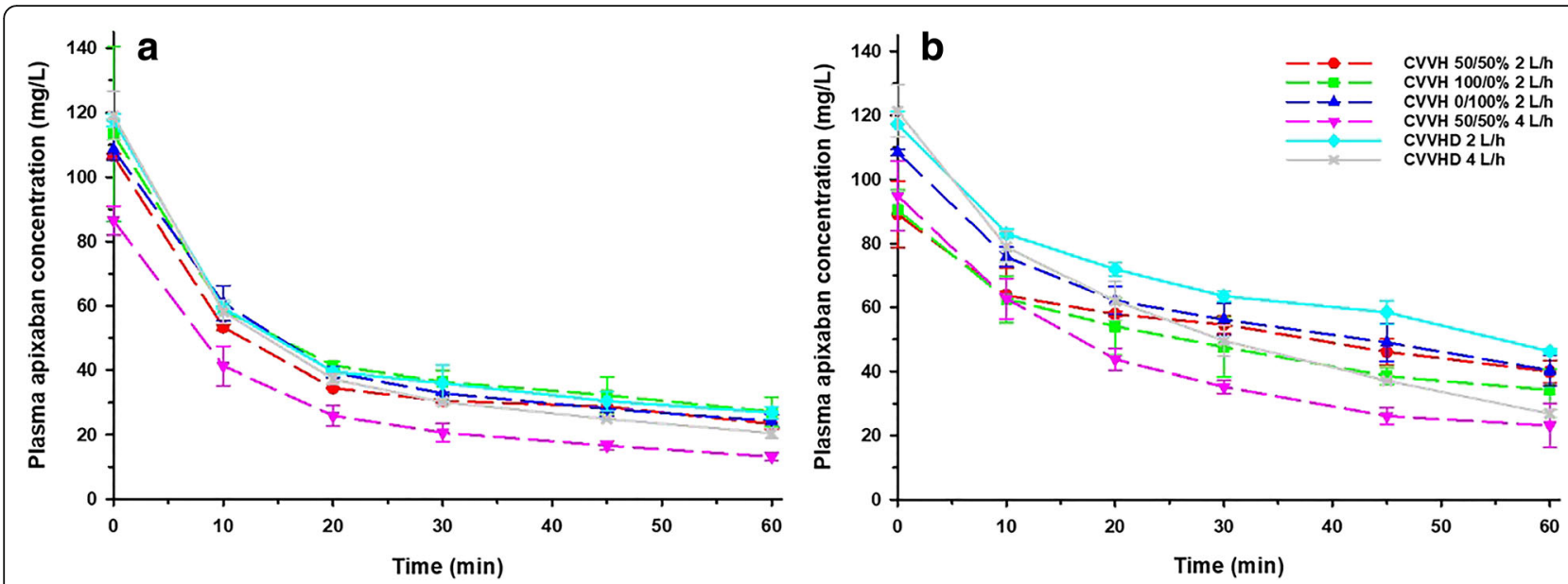

Fig. 1 Pre-filter plasma concentration-time profiles of apixaban during CWH and CWHD at each rate and point of dilution with the HF1400 filter (a) and M150 filter (b). Mean values are displayed with error bars representing standard deviations

Table 2 displays the observed SC, SA, and $\mathrm{CL}_{\mathrm{TM}}$ by $\mathrm{SC} / \mathrm{SA}$ values of apixaban and urea during $\mathrm{CVVH}$ and CVVHD stratified by CRRT mode, filter type, flow rate, and point of replacement fluid dilution. As expected, $\mathrm{CL}_{\mathrm{TM}}$ by $\mathrm{SC} / \mathrm{SA}$ values scaled roughly proportional to increases in flow rate from 2 to $4 \mathrm{~L} / \mathrm{h}$ during $\mathrm{CVVH}$ $(1.86-2.34 \mathrm{~L} / \mathrm{h})$ and CVVHD $(1.94 \mathrm{~L} / \mathrm{h})$. The mean apixaban SC value during CVVH with the M150 filter was 0.584 and 0.594 with HF1400 $(P=0.726)$ and mean SA during CVVHD was 0.587 with M150 and 0.612 with

Table 2 Transmembrane clearance of apixaban and urea during in vitro CRRT as determined by SC or SA * flow rate ${ }^{a}$

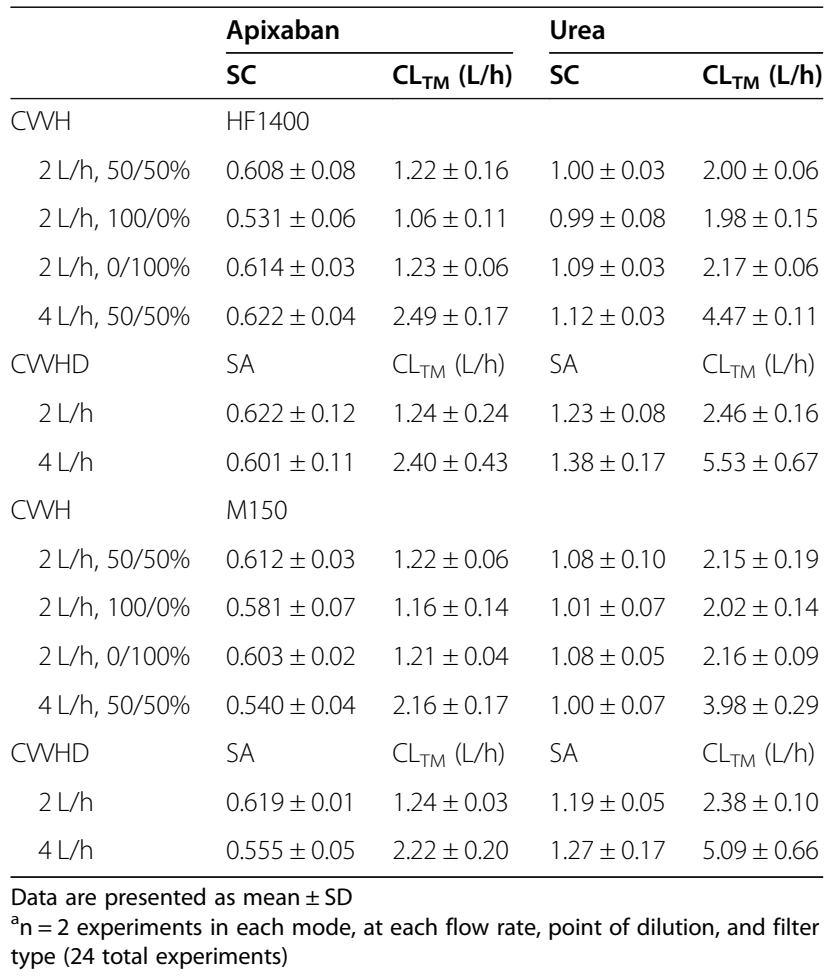

HF1400 $(P=0.543)$. The average SC across CVVH was 0.589 and SA across CVVHD was $0.599(P=0.628)$. The overall mean SC/SA for apixaban was 0.594 across all CRRT modes, filter types, flow rates, and points of replacement fluid dilution tested, while overall mean $\mathrm{CL}_{\mathrm{TM}}$ by SC/SA at 2 and $4 \mathrm{~L} / \mathrm{h}$ were 1.2 and $2.4 \mathrm{~L} / \mathrm{h}$, respectively. Urea $\mathrm{SC}, \mathrm{SA}$, and $\mathrm{CL}_{\mathrm{TM}}$ values were comparable to previously established parameters obtained in analogous experimental conditions [57].

\section{Effect of CVVH point of dilution}

Within the HF1400 filter group, there were no significant differences in $\mathrm{CL}_{\mathrm{TM}}$ by AUC across any of the 3 points of dilution at $2 \mathrm{~L} / \mathrm{h}(P=0.641)$, however, when evaluated as $\mathrm{CL}_{\mathrm{TM}}$ by $\mathrm{SC}$, there were significant differences noted between the $50 / 50 \%$ and both the $0 / 100 \%$ $(P=0.009)$ and $100 / 0 \%$ modes $(P=0.014)$. Within the M150 group, point of replacement fluid addition also did not affect $\mathrm{CL}_{\mathrm{TM}}$ by AUC $(P=0.420)$, but again demonstrated significant differences between the $50 / 50 \%$ and both the $0 / 100 \%(P=0.003)$ and $100 / 0 \% \quad(P=0.004)$ groups by $\mathrm{SC}$.

\section{Effect of filter type}

At $2 \mathrm{~L} / \mathrm{h}$, filter type did significantly affect $\mathrm{CL}_{\mathrm{TM}}$ by AUC where the mean $\mathrm{CL}_{\mathrm{TM}}$ was $1.80 \mathrm{~L} / \mathrm{h}(95 \% \mathrm{CI} 1.56-$ 2.05) for the HF1400 filter vs $1.12 \mathrm{~L} / \mathrm{h}$ (95\% CI $0.87-$ $1.37)$ for the M150 filter $(P=0.001)$. No difference was observed at $4 \mathrm{~L} / \mathrm{h}: \quad 3.30 \mathrm{~L} / \mathrm{h} \quad(95 \% \mathrm{CI} \quad 0.63-5.97)$ for HF1400 and $2.07 \mathrm{~L} / \mathrm{h}(95 \% \mathrm{CI}-2.12-6.26)$ for M150 ( $P=$ 0.088 ), although there were only 2 experiments per group at this rate. Including both flow rates, mean $\mathrm{CL}_{\mathrm{TM}}$ values by AUC differed significantly between filters (HF1400 $2.18 \mathrm{~L} / \mathrm{h}, 95 \%$ CI $1.57-2.78$ vs. M150 $1.36 \mathrm{~L} / \mathrm{h}$, 95\% CI 0.93-1.79, $P=0.021$ ). 
For $\mathrm{CL}_{\mathrm{TM}}$ by $\mathrm{SC} / \mathrm{SA}$ at $2 \mathrm{~L} / \mathrm{h}$, filter type did not have a significant effect with mean $\mathrm{CL}_{\mathrm{TM}}$ values of $1.44 \mathrm{~L} / \mathrm{h}$ (95\% CI $0.97-1.91)$ for HF1400 and $1.51 \mathrm{~L} / \mathrm{h}$ (95\% CI $0.97-2.04)$ for $\mathrm{M} 150(P=0.810)$. There was also no difference observed at $4 \mathrm{~L} / \mathrm{h}: 2.49 \mathrm{~L} / \mathrm{h}(95 \%$ CI $0.58-4.39)$ for HF1400 and $2.16 \mathrm{~L} / \mathrm{h}$ (95\% CI $0.89-3.43)$ for M150 $(P=0.209)$. Including both flow rates, mean $\mathrm{CL}_{\mathrm{TM}}$ values by $\mathrm{SC} / \mathrm{SA}$ remained similar between filters (HF1400 1.70 L/h, 95\% CI $1.18-2.22$ vs. M150 1.67 L/h, 95\% CI 1.23-2.11, $P=0.915)$.

\section{Effect of point of dilution and filter type $\mathrm{CVVH}$}

These results were confirmed via a two-way ANOVA which demonstrated that the interaction between point of dilution and filter type was not significant on $\mathrm{CL}_{\mathrm{TM}}$ by $\operatorname{AUC}(P=0.292)$ or by SC $(P=0.519)$ at $2 \mathrm{~L} / \mathrm{h}$. An analysis of the main effects of each variable indicated that there was a significant difference in $\mathrm{CL}_{\mathrm{TM}}$ by AUC according to filter type $(P=0.003)$ but not point of dilution $(P=0.922)$, as previously described (Fig. 2). Conversely, $\mathrm{CL}_{\mathrm{TM}}$ by $\mathrm{SC}$ again differed significantly by point of dilution $(P<0.001)$ but not by filter type $(P=0.304)$. As only one point of dilution $(50 / 50 \%)$ was tested at the $4 \mathrm{~L} / \mathrm{h}$ rate (2 experiments), two-way ANOVAs were not performed. Ignoring flow rate generated similar results with a non-significant interaction between filter type and point of dilution for $\mathrm{CL}_{\mathrm{TM}}$ by $\mathrm{AUC}(P=0.648)$ and by SC $(P=0.792)$ while main effects continued to differ according to filter type for $\mathrm{CL}_{\mathrm{TM}}$ by $\operatorname{AUC}(P=0.049)$ but not point of dilution $(P=0.238)$ and vice versa for $\mathrm{CL}_{\mathrm{TM}}$ by SC $(P=0.904$ for filter type and $P<0.001$ for dilution).

\section{CVVHD}

Similarly for CVVHD at $2 \mathrm{~L} / \mathrm{h}$, there was a significant difference in mean $\mathrm{CL}_{\mathrm{TM}}$ by $\mathrm{AUC}$ based on filter type (HF1400 1.67 L/h, 95\% CI 0.08-3.25 vs. M150 $0.91 \mathrm{~L} / \mathrm{h}$, 95\% CI $0.46-1.35, P=0.028)$. This difference remained at $4 \mathrm{~L} / \mathrm{h}$ with mean $\mathrm{CL}_{\mathrm{TM}}$ by AUC values of $2.17 \mathrm{~L} / \mathrm{h}$ (95\% CI $0.96-3.37)$ for HF1400 and $1.63 \mathrm{~L} / \mathrm{h}$ (95\% CI $0.99-2.27)$ for $\mathrm{M} 150(P=0.038)$. For $\mathrm{CL}_{\mathrm{TM}}$ by $\mathrm{SA}$, mean values did not differ at $2 \mathrm{~L} / \mathrm{h}$ (HF1400 $1.25 \mathrm{~L} / \mathrm{h}, 95 \% \mathrm{CI}$ 0.93-1.56 vs. M150 1.24 L/h, 95\% CI 0.73-1.75, $P=$ $0.925)$ or $4 \mathrm{~L} / \mathrm{h}$ (HF1400 $2.41 \mathrm{~L} / \mathrm{h}, 95 \%$ CI $1.71-3.10$ vs. M150 2.23 L/h, 2.16-2.29, $P=0.083$ ). Ignoring flow rate, mean $\mathrm{CL}_{\mathrm{TM}}$ by AUC values remained significantly higher for HF1400 (1.92 L/h, 95\% CI 1.41-2.42) compared to the M150 $(1.27 \mathrm{~L} / \mathrm{h}, 95 \%$ CI $0.60-1.94, P=$ 0.049 ) but did not differ significantly for $\mathrm{CL}_{\mathrm{TM}}$ by $\mathrm{SA}$ (HF1400 1.83 L/h, 95\% CI 0.76-2.89 vs. M150 $1.73 \mathrm{~L} / \mathrm{h}$, 95\% CI 0.83-2.64, $P=0.841)$.

\section{Effect of CRRT mode, filter type, and flow rate}

Ignoring point of dilution, the three-way ANOVA for the effect of CRRT mode, filter type, and flow rate on $\mathrm{CL}_{\mathrm{TM}}$ by AUC demonstrated no significant two-way interactions between CRRT mode and filter $(P=0.176)$ or filter and flow rate $(P=0.475)$, while CRRT mode and flow rate was significant at $P=0.013$ (Fig. 3). The three-

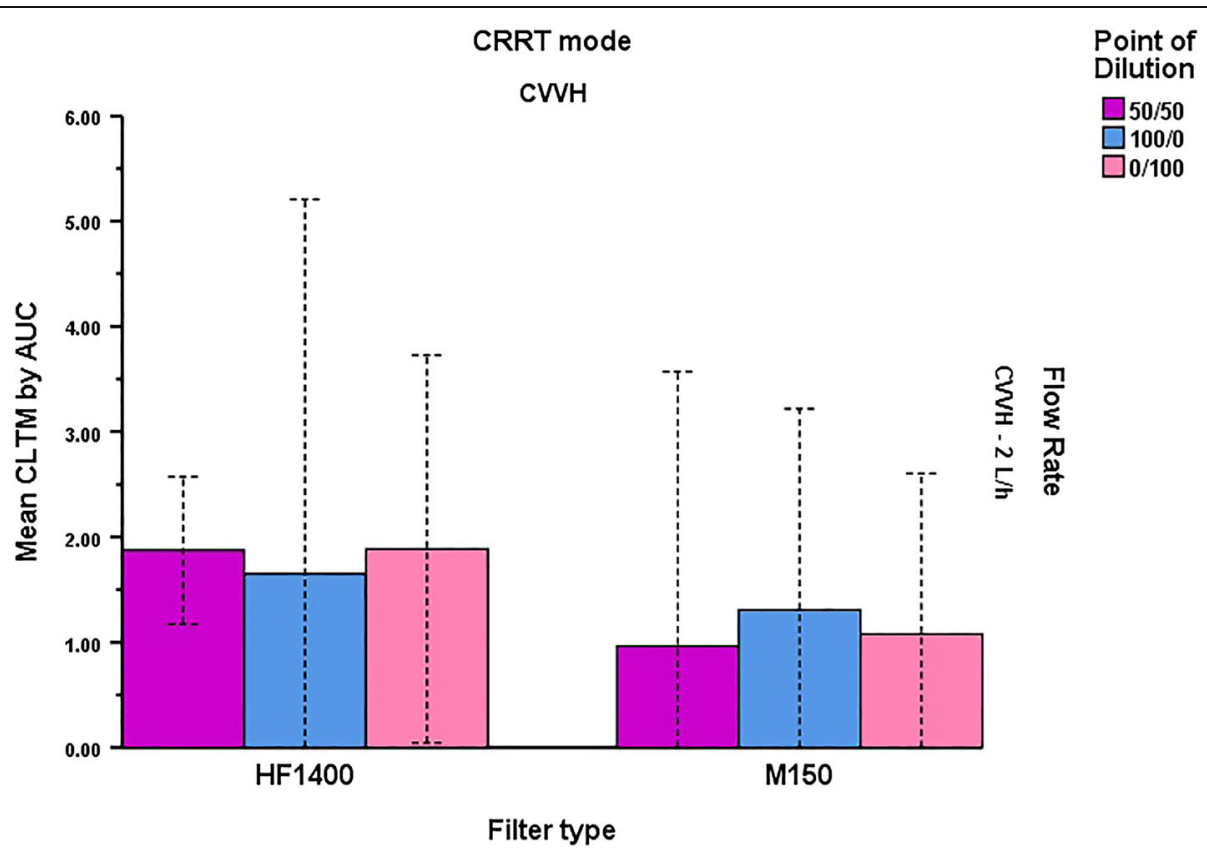

Fig. 2 Mean $\mathrm{CL}_{\mathrm{TM}}$ by $\mathrm{AUC}$ of apixaban during $\mathrm{CWH}$ at $2 \mathrm{~L} / \mathrm{h}$ according to point of dilution and filter type. Bars represent mean values with $95 \%$ confidence intervals displayed as dashed lines 


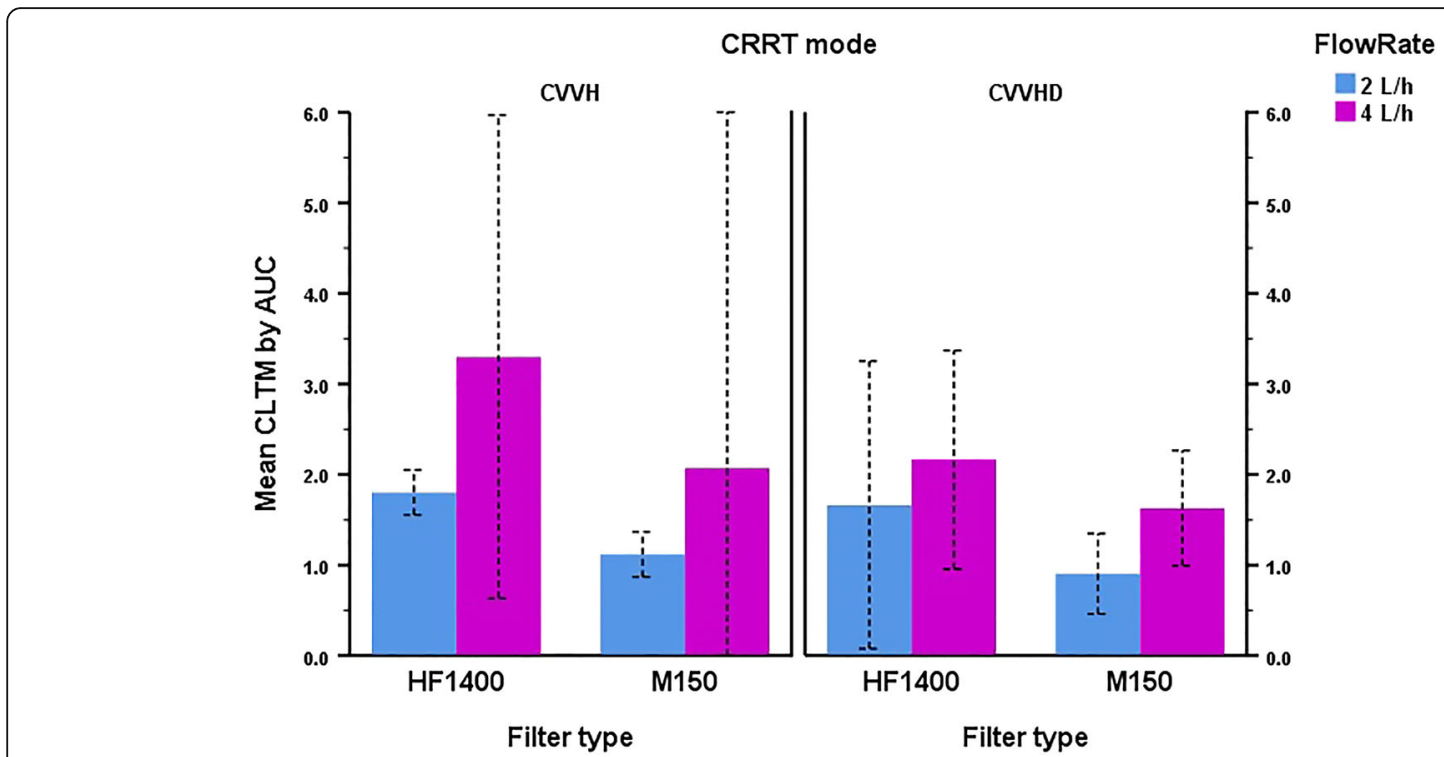

Fig. 3 Mean $\mathrm{CL}_{\mathrm{TM}}$ by AUC of apixaban during in vitro CRRT according to mode, flow rate, and filter type. Bars represent mean values with 95\% confidence intervals displayed as dashed lines

way interaction between CRRT mode, filter, and flow rate was also non-significant $(P=0.098)$ with an adjusted $\mathrm{R}^{2}$ of 0.869 . For the $\mathrm{CL}_{\mathrm{TM}}$ by $\mathrm{SC} / \mathrm{SA}$ model, all two-way interactions were non-significant (CRRT mode*filter, $P=0.914$, filter*flow rate, $P=0.427$, and CRRT mode*flow rate, $P=0.540$ ) along with the three-way interaction (CRRT mode"filter"flow rate, $P=0.755$, adjusted $R^{2}=$ 0.516). The estimated marginal means for $\mathrm{CL}_{\mathrm{TM}}$ by AUC and SC/SA generated from these ANOVAs as a function of CRRT mode, filter type, and flow rate are displayed in Table 3.

\section{Adsorption experiments}

The extent of apixaban adsorbed to the CRRT circuit was evaluated across two duplicate experiments with serial samples collected over a span of $180 \mathrm{~min}$; with each filter type in CVVH mode at a flow rate of $2 \mathrm{~L} / \mathrm{h}$ with a 50/50\% dilution scheme. The intra-assay CV\% within the HF1400 filter experiments was 5.55 and $10.05 \%$ for the M150 filter. Overall, the mean $( \pm S D)$ percent adsorption differed significantly between the HF1400 and M150 filter types at $38.1 \pm 13.4 \%$ and $12.8 \pm 11.2 \%(P<0.001)$. The concentration-time profiles during these experiments are displayed in Supplementary Fig. 1 in which adsorption peaks at 10 min for both filter types, although the amount adsorbed to the M150 filter is roughly half that of the HF1400. While the rate and magnitude of decline in adsorption to the HF1400 filter was significantly less than that of the M150, there was no clear evidence of filter saturation. Regardless of filter type, adsorption appeared reversible corresponding to decreasing circulating apixaban concentrations.

\section{Protein binding}

The protein binding of apixaban has been previously explored in the serum of rats, dogs, chimpanzees, and humans but never in bovine plasma [58]. Protein binding in these species has ranged from $87 \%$ in humans to $96 \%$ in rats and varied slightly by concentration. Given its impact on drug clearance during CRRT, the protein Table 3 Three-way ANOVA-generated marginal means of $\mathrm{CL}_{T M}$ by CRRT mode, filter type, and flow rate

\begin{tabular}{|c|c|c|c|c|c|}
\hline \multicolumn{6}{|c|}{$\mathrm{CL}_{\mathrm{TM}}$ by $\mathrm{SC}$ or $\mathrm{SA}$} \\
\hline CRRT mode & Filter type & Flow rate $(\mathrm{L} / \mathrm{h})$ & $\mathrm{CL}_{\mathrm{TM}}(\mathrm{L} / \mathrm{h})$ & $95 \% \mathrm{Cl}$ & SE \\
\hline \multirow[t]{4}{*}{$\mathrm{CWH}$} & \multirow[t]{2}{*}{ HF1400 } & 2 & 1.438 & $1.105-1.772$ & 0.157 \\
\hline & & 4 & 2.490 & $1.913-3.067$ & 0.272 \\
\hline & \multirow[t]{2}{*}{ M150 } & 2 & 1.507 & $1.173-1.840$ & 0.157 \\
\hline & & 4 & 2.160 & $1.583-2.737$ & 0.272 \\
\hline \multirow[t]{4}{*}{ CWHD } & \multirow[t]{2}{*}{ HF1400 } & 2 & 1.245 & $0.668-1.822$ & 1.245 \\
\hline & & 4 & 2.405 & $1.828-2.982$ & 2.405 \\
\hline & \multirow[t]{2}{*}{ M150 } & 2 & 1.240 & $0.663-1.817$ & 0.272 \\
\hline & & 4 & 2.225 & $1.648-2.802$ & 0.272 \\
\hline \multicolumn{6}{|l|}{$\mathrm{CL}_{\mathrm{TM}}$ by $\mathrm{AUC}$} \\
\hline \multirow[t]{4}{*}{$\mathrm{CWH}$} & \multirow[t]{2}{*}{ HF1400 } & 2 & 1.803 & $1.596-2.011$ & 0.980 \\
\hline & & 4 & 3.300 & $2.941-3.659$ & 0.170 \\
\hline & \multirow[t]{2}{*}{ M150 } & 2 & 1.118 & $0.911-1.326$ & 0.098 \\
\hline & & 4 & 2.070 & $1.711-2.429$ & 0.170 \\
\hline \multirow[t]{4}{*}{ CWHD } & \multirow[t]{2}{*}{ HF1400 } & 2 & 1.665 & $1.306-2.024$ & 0.170 \\
\hline & & 4 & 2.165 & $1.806-2.524$ & 0.170 \\
\hline & \multirow[t]{2}{*}{ M150 } & 2 & 0.905 & $0.546-1.264$ & 0.170 \\
\hline & & 4 & 1.630 & $1.271-1.989$ & 0.170 \\
\hline
\end{tabular}

SE standard error 
binding of apixaban to bovine plasma from 4 contrived plasma samples with a measured bovine albumin concentration of $3.597 \mathrm{mg} / \mathrm{dL}$ (Biologic Resources Laboratory, University of Illinois at Chicago, Chicago, IL, USA) was evaluated. Samples were spiked at the human simulated $\mathrm{C}_{\max }$ and $0.5 \mathrm{x} \mathrm{C}_{\max }$ concentration [47]. Overall, the mean $( \pm S D)$ percent protein binding in bovine plasma was $70.81 \pm 0.01 \%$ with an intra-assay $\mathrm{CV} \%$ of $4.2 \%$ at $\mathrm{C}_{\max }$ and $1.2 \%$ at $0.5 \mathrm{x} \mathrm{C}_{\max }$.

\section{Optimal CRRT dose determination}

Given the increased precision of $\mathrm{CL}_{\mathrm{TM}}$ by AUC compared to SC/SA [59], lack of influence by point of dilution, and improved model fit (adjusted $R^{2} 0.87$ vs. 0.52 ), these values were used to generate optimal dosing recommendations generalizable across varying CRRT modalities. All 4 applicable covariates (CRRT mode, filter type, flow rate, and point of dilution) were entered into the multiple linear regression model (Table 4). Filter type and flow rate were significant, and therefore, retained in the final model demonstrating a decrease of $0.821 \mathrm{~L} / \mathrm{h}(95 \% \mathrm{CI}-1.13$ to $-0.509, P<0.001)$ in $\mathrm{CL}_{\mathrm{TM}}$ when switching from the HF1400 to M150 filter and an increase of $0.612 \mathrm{~L} / \mathrm{h}(95 \% \mathrm{CI} 0.864-1.585, P<0.001)$ in $\mathrm{CL}_{\mathrm{TM}}$ for every $1 \mathrm{~L} / \mathrm{h}$ increase in flow rate with excellent correlation (adjusted $R^{2}=0.849$ ). This regression equation was then used to make predictions for $\mathrm{CL}_{\mathrm{TM}}$ and estimate optimal dosing recommendations for apixaban during CRRT across filter types and simulated flow rates from $0.5-5 \mathrm{~L} / \mathrm{h}$ (Table 5). Although renal clearance $\left(\mathrm{CL}_{\mathrm{R}}\right)$ typically only accounts for approximately $27 \%$ of the $\mathrm{CL}_{\mathrm{T}}$ of apixaban [46], mean observed $\mathrm{CL}_{\mathrm{TM}}$ values account for up to $60 \%$ of $\mathrm{CL}_{\mathrm{T}}$ at the highest flow rates simulated in this model (Table 5). As such, the labeled dose of $5 \mathrm{mg}$ twice (BID) would be appropriate for 60 $90 \%$ of the simulated flow rates, depending on filter type. Given the direct correlation between apixaban concentrations and its pharmacodynamic activity, along with its well-established safety profile at doses up to $50 \mathrm{mg}$ daily for 3-7 days (AUC up to $6045 \mathrm{ng} \cdot \mathrm{h} / \mathrm{mL}$ ) [33, 46], we feel these doses are appropriate to maximize the efficacy and safety of apixaban and match the desired systemic exposure in patients with increased $\mathrm{CL}_{\mathrm{T}}$ due to high

Table 4 Multiple linear regression between tested covariates and $\mathrm{CL}_{T M}$ by $\mathrm{AUC}$

\begin{tabular}{llll}
\hline Variable & Unstandardized $\boldsymbol{\beta}$ & $\mathbf{9 5 \% ~ C l}$ & $\boldsymbol{P}$ value \\
\hline Constant & 1.469 & $0.800-2.137$ & $<0.001$ \\
Filter type $^{\mathrm{a}}$ & -0.821 & $-1.133--0.509$ & $<0.001$ \\
Flow rate $(\mathrm{L} / \mathrm{h})$ & 0.612 & $0.864-1.585$ & $<0.001$ \\
\hline
\end{tabular}

${ }^{\mathrm{a}} \mathrm{HF} 1400=1, \mathrm{M} 150=2$

Variables entered: CRRT mode, filter type, flow rate, and point of dilution Adjusted $\mathrm{R}^{2}=0.849$

Regression equation: $\mathrm{CL}_{\mathrm{TM}}=1.469 \mathrm{~L} / \mathrm{h}+(-0.821$ * filter type $)+(0.612$ * flow rate $(\mathrm{L} / \mathrm{h}))$
CRRT flow rates. Maintaining single doses $\leq 10 \mathrm{mg}$ also ensures that its linear PK properties are preserved, and that dissolution-limited absorption and decreases in bioavailability are avoided.

\section{Discussion}

To our knowledge this is the first study to evaluate the $\mathrm{CL}_{\mathrm{TM}}$ of apixaban during CRRT and provides the first set of PK information for which to guide optimal dosing. Our data demonstrate that although it is considered highly protein bound (87\%) and minimally renally excreted (27\%), the estimated removal of apixaban during CRRT accounted for up to $60 \%$ of total clearance and necessitated doses at or above the standard labeled dosage to achieve target therapeutic AUC values [31]. These results underscore the need to thoroughly evaluate the extracorporeal removal of drugs in tightly controlled, rigorous in vitro settings rather than estimating the potential removal using drug- and/or CRRT-specific factors, which has shown to be misleading in previous investigations [60], or by extrapolating from data generated from patients on intermittent hemodialysis [33, 61]. This is especially true as the use of apixaban for therapeutic anticoagulation continues to increase among critically ill ICU patients [8, 62-64], many if not most of whom will require CRRT at some point during their hospitalization.

In addition to providing clinicians with the first set of data for which to guide dosing of apixaban during CRRT, our study has several other notable strengths. Primarily, our methodology for assessing true $\mathrm{CL}_{\mathrm{TM}}$ employed a rich PK sampling scheme and thorough statistical analyses which significantly improved our ability to accurately estimate drug removal during CRRT. The majority of previous studies employ a single sample design and attempt to estimate $\mathrm{CL}_{\mathrm{TM}}$ by multiplying $\mathrm{SC}$ or SA derived from a single time point by the flow rate [65-68]. These methods falsely assume SC and SA are static over time and that $\mathrm{CL}_{\mathrm{TM}}$ is directly proportional to flow rate across the continuum of CRRT settings. Moreover, the methods used for calculating SC, SA, and $\mathrm{CL}_{\mathrm{TM}}$ have varied dramatically throughout the literature, even among the same authors/groups across different studies [50,69-75], especially with regards to the influence of point of dilution during CVVH (Supplementary Fig. 2). Therefore, our optimal dosing regimens were generated exclusively via noncompartmental analyses given its increased precision, lack of influence by point of dilution, and improved model fit. Additionally, point of dilution was the only covariate not retained in our final multiple linear regression (Table 4), further underscoring its lack of impact.

Finally, we also assessed the effect of protein binding and adsorption on the clearance of apixaban during 
Table 5 Optimal dosing recommendations of apixaban by filter type and CRRT flow rate

\begin{tabular}{|c|c|c|c|c|c|c|c|c|c|}
\hline \multirow[b]{2}{*}{$\begin{array}{l}\text { CRRT } \\
\text { flow rate } \\
\text { (L/h) }\end{array}$} & \multicolumn{2}{|c|}{ Mean $\mathrm{CL}_{\mathrm{TM}}(\mathrm{L} / \mathrm{h})$} & \multirow[b]{2}{*}{$\begin{array}{l}\text { Mean } \\
\mathrm{CL}_{\mathrm{NR}} \\
(\mathrm{L} / \mathrm{h})^{\mathrm{a}}\end{array}$} & \multicolumn{2}{|c|}{ Mean $\mathrm{CL}_{\mathrm{T}}(\mathrm{L} / \mathrm{h})$} & \multicolumn{4}{|c|}{ Optimal total daily dose $(\mathrm{mg})^{\mathrm{c}}$} \\
\hline & HF1400 Filter & M150 Filter & & $\begin{array}{l}\text { HF1400 } \\
\text { Filter }\end{array}$ & $\begin{array}{l}\text { M150 } \\
\text { Filter }\end{array}$ & $\begin{array}{l}\text { Target } \\
\text { AUC } \\
(\mathrm{ng} \cdot \mathrm{h} / \mathrm{mL})^{\mathrm{b}}\end{array}$ & $\begin{array}{l}\text { HF1400 } \\
\text { Filter }\end{array}$ & $\begin{array}{l}\text { M150 } \\
\text { Filter }\end{array}$ & Optimal dosing regimen ${ }^{d}$ \\
\hline 0.5 & 0.95 & 0.13 & 2.52 & 3.47 & 2.65 & 2103.8 & 7.31 & 5.58 & $2.5 \mathrm{mg} \mathrm{BID}$ \\
\hline 1 & 1.26 & 0.44 & 2.52 & 3.78 & 2.96 & 2103.8 & 7.95 & 6.23 & $2.5-5 \mathrm{mg} \mathrm{BID}$ \\
\hline 1.5 & 1.57 & 0.75 & 2.52 & 4.09 & 3.27 & 2103.8 & 8.60 & 6.87 & 2.5-5 mg BID \\
\hline 2 & 1.87 & 1.05 & 2.52 & 4.39 & 3.57 & 2103.8 & 9.24 & 7.51 & 5 mg BID \\
\hline 2.5 & 2.18 & 1.36 & 2.52 & 4.70 & 3.88 & 2103.8 & 9.88 & 8.16 & 5 mg BID \\
\hline 3 & 2.48 & 1.66 & 2.52 & 5.00 & 4.18 & 2103.8 & 10.53 & 8.80 & 5 mg BID \\
\hline 3.5 & 2.79 & 1.97 & 2.52 & 5.31 & 4.49 & 2103.8 & 11.17 & 9.44 & $5 \mathrm{mg} \mathrm{BID}$ \\
\hline 4 & 3.10 & 2.28 & 2.52 & 5.62 & 4.80 & 2103.8 & 11.82 & 10.09 & $5 \mathrm{mg} \mathrm{BID}$ \\
\hline 4.5 & 3.40 & 2.58 & 2.52 & 5.92 & 5.10 & 2103.8 & 12.46 & 10.73 & 5 mg BID \\
\hline 5 & 3.71 & 2.89 & 2.52 & 6.23 & 5.41 & 2103.8 & 13.10 & 11.38 & $5-7.5 \mathrm{mg} \mathrm{BID}$ \\
\hline
\end{tabular}

${ }^{a}$ Estimated $\mathrm{CL}_{\mathrm{NR}}$ from Byon et al. CPT Pharmacometrics Syst Pharmacol 2017;6(5):340-349

${ }^{\mathrm{b}}$ Target AUC from Frost et al. Br J Clin Pharmacol 2013;76:776-786

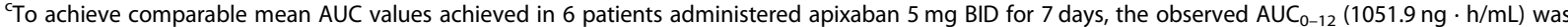
multiplied by two to estimate $A \cup C_{0-24}$ and solve for dose via the equation $A U C=$ total daily dose $/ \mathrm{CL}_{T}$

${ }^{\mathrm{d}}$ Rounded to the nearest $2.5 \mathrm{mg}$ tablet

CRRT. Although protein binding is known to be one of the most important factors affecting drug removal during CRRT [76], exceedingly few agents have available data regarding binding to bovine plasma as these animals are not typically utilized in the drug development process [77]. As the measured protein binding of apixaban in bovine plasma in our study was within $20 \%$ of that observed in healthy volunteers, it is unlikely that this significantly altered our optimal dosing recommendations. While crystalloid solutions are often used as the vehicle for drug delivery during in vitro CRRT studies due to accessibility and low cost $[53,78,79]$, these solutions lack blood proteins vital for facilitating drugprotein binding and do not allow for the formation of a protein or fibrin layer on the extracorporeal circuit and hemodialyzer membrane. Albeit the use of modern, highly biocompatible hemofilters has often made drug adsorption negligible compared to the effect of filtration, it is critical to evaluate this component of removal from the circuit especially for moderately water soluble, lipophilic drugs like apixaban. Given that peak adsorption almost always occurs within the first $5-30 \mathrm{~min}$ of CRRT $[66,80,81]$, our $180 \mathrm{~min}$ experiments allowed ample time for the deposition of blood proteins to the hemofilter and circuit in order to assess the reversibility or saturation point of apixaban adsorption [82]. We observed degrees of filter adsorption high enough to potentially effect drug dosing during CRRT in addition to filtration, particularly for the HF1400 filter, which necessitated filter-specific dosing recommendations as displayed in Table 5. This observed diparity between the two filter types is likely due to differences in their composition, as previously described $[66,81,83]$.
Despite these strengths, our study is not without limitations. First, although as many different CRRT machines, filter types, dilution points, and flow rates as possible were included, the results may not be representative of all modalities of CRRT. Second, we assumed non-renal drug clearance to be stable when estimating dosing recommendations. Although there are some data to suggest AKI may affect non-renal clearance [84], there are currently no practical methods or useful biomarkers to assess changes in non-renal clearance. Third, the lower protein binding of apixaban in bovine plasma compared to humans may have led to increased CRRT clearance and subsequently increased dosing recommendation, although hypoalbuminemia is a common phenomenon among ICU patients undergoing CRRT [85]. Fourth, as mentioned, the necessity of forming a closed system may falsely inflate the degree of filter adsorption observed in vitro as virtually all of the drug in the blood continuously encounters the hemofilter and CRRT circuit, therefore precipitating the maximal degree of drug-filter interaction and adsorptive loss [66]. In addition, the utilization of a new hemofilter and circuit for each experiment may have limited our ability to fully assess the effect of filter life on adsorption and $\mathrm{CL}_{\mathrm{TM}}$ as well as the impact of repeated apixaban dosing. Due to the complicated logistics of in vitro adsorption experiments, caution should be taken when interpreting these data [86]. Lastly, as the PK of apixaban has already been extensively described [56], our 1-h PK sampling scheme in this study was designed solely to evaluate the $\mathrm{CL}_{\mathrm{TM}}$ of apixaban during CRRT, and therefore, the half-lives reported should be interpreted in light of this. 


\section{Conclusion}

As recognized by the FDA, NIH, and NIAID, nonclinical PK/PD models play a critical role in designing human dosage regimens and are essential tools for drug development and dose optimization in special populations [43]. This study thoroughly explored the PK and dialytic clearance of apixaban during CRRT during tightly controlled in vitro experimentation. Apixaban was approximately $70 \%$ bound to bovine plasma and demonstrated variable adsorption to the HF1400 and M150 filters at approximately 38 and 13\%, respectively. Clearance of apixaban during CRRT was most accurately estimated via calculation of $\mathrm{CL}_{\mathrm{TM}}$ through noncompartmental estimation of AUC, as opposed to utilizing the product of SC/SA and flow rate. For CRRT flow rates most commonly employed in clinical practice [87], the standard labeled $5 \mathrm{mg}$ BID dose of apixaban is predicted to achieve target systemic exposure thresholds. The safety and efficacy of these proposed dosing regimens warrants further investigation in in vivo studies of critically ill patients undergoing CRRT.

\section{Supplementary Information}

The online version contains supplementary material available at https://doi. org/10.1186/s12882-021-02248-7.

Additional file 1: Supplemental Figure 1. Central reservoir plasma concentration-time profiles of apixaban within closed-circuit adsorption experiments with each filter type. Mean values are displayed with error bars representing standard deviations.

Additional file 2: Supplemental Figure 2. Variations in sieving coefficient (SC) during CWH according to location of replacement fluid infusion, method used for calculation, and inclusion or exclusion of a dilutional correction factor (CF). Sampling locations are as follows: 1) undiluted (pre; 2) diluted (pre; 3) undiluted (post; 4) diluted Cpost; 5) Cuf.

\section{Abbreviations}

AKI: Acute kidney injury; AN69: Acrylonitrile; ANOVA: Analysis of variance; aPTT: Activated thromboplastin time; AUC: Area under the curve; $\mathrm{AUC}_{0-\infty}$ : Area under the curve from time zero to infinity; $\mathrm{AUC}_{0-24}$ : Area under the curve from time zero to $24 \mathrm{~h}$; $A \cup C_{0 \text {-last: }}$ Area under the curve from time zero to last measurable concentration; BID: Twice daily;

$C_{\text {dialysate: }}$ Concentration in the dialysate; $C_{\text {last }}$ : Last observed plasma concentration; $C_{\text {max }}$ : Maximum plasma concentration; $C_{\text {post }}$ : Concentration from the post-filter sampling port; $C_{\text {pre: }}$ : Concentration from the pre-filter sampling port; $C_{\text {uf: }}$ Concentration in the ultrafiltrate; $\mathrm{Cl}$ : Confidence interval; $\mathrm{CL}$ : Clearance; $\mathrm{CL}_{\mathrm{CWH}}$ : Continuous veno-venous hemofiltration clearance; $\mathrm{CL}_{C W H D}$ : Continuous veno-venous hemodialysis clearance; $\mathrm{CL}_{\mathrm{NR}}$ : Non-renal clearance; $\mathrm{CL}_{R}$ : Renal clearance; $\mathrm{CL}_{\mathrm{T}}$ : Total body clearance;

$\mathrm{CL}_{\text {TM: }}$ : Transmembrane clearance; CRRT: Continuous renal replacement therapy; CV: Coefficient of variance; $\mathrm{CWH}$ : Continuous veno-venous hemofiltration; CWHD: Continuous veno-venous hemodialysis; DOAC: Direct oral anticoagulant; ESRD : End stage renal disease; FDA: Food and Drug Administration; HD: Hemodialysis; ICU: Intensive care unit; $\mathrm{K}_{\mathrm{e}}$ : Elimination rate constant; LMWH: Low molecular weight heparin; NIAID: National Institute of Allergy and Infectious Diseases; NIH: National Institute of Health; NOAF: Newonset atrial fibrillation; PAES: Polyarylethersulfone; PD : Pharmacodynamics; PK: Pharmacokinetics; $Q_{b}$ : Blood flow rate; $Q_{d}$ : Dialysate flow rate; $Q_{r e p}$ : Prefilter replacement fluid rate; $Q_{\text {uf: }}$ Ultrafiltrate or replacement fluid flow rate; QC: Quality control; RE: Relative error; RRT: Renal replacement therapy; SA: Saturation coefficient; SC: Sieving coefficient; SD: Standard deviation; $t_{1 / 2}$ : Half-life; TDD: Total daily dose; UFH: Unfractionated heparin; $V_{d}$ : Volume of distribution; VTE: Venous thromboembolism

\section{Acknowledgements}

Not applicable.

\section{Authors' contributions}

E.W. and S.B. conceptualized and designed the study, provided study oversight, and assisted with data analysis and manuscript writing. L.A. and X.T. performed the experiments and drafted the initial versions of the manuscripts. All authors contributed significantly and read and approved the final version of the manuscript.

\section{Funding}

This work was supported by an investigator-initiated research grant awarded to S.B. by Bristol-Myers Squibb. The sponsor was not involved in the study design, procedures, analysis, interpretation of data, or in writing the manuscript.

\section{Availability of data and materials}

The datasets generated and/or analyzed during the current study are not publicly available due confidentiality agreements with the study sponsor but may be available from the corresponding author on reasonable request.

Ethics approval and consent to participate

Not applicable.

Consent for publication

Not applicable.

\section{Competing interests}

E.W. serves on the speaker's bureau for Allergan PIc, Melinta Therapeutics, and Astellas Pharma and on the advisory board for GenMark Diagnostics and Shionogi. All other authors declare that they have no competing interests.

Received: 12 August 2020 Accepted: 19 January 2021

Published online: 30 January 2021

\section{References}

1. Kaplan D, Casper TC, Elliott CG, Men S, Pendleton RC, Kraiss LW, Weyrich AS, Grissom CK, Zimmerman GA, Rondina MT. VTE incidence and risk factors in patients with severe Sepsis and septic shock. Chest. 2015;148(5):1224-30.

2. Khanna R, Maynard G, Sadeghi B, Hensley L, Medvedev S, Danielsen B, White $\mathrm{RH}$. Incidence of hospital-acquired venous thromboembolic codes in medical patients hospitalized in academic medical centers. J Hosp Med. 2014:9(4):221-5.

3. Malhotra AK, Goldberg SR, McLay L, Martin NR, Wolfe LG, Levy MM, Khiatani V, Borchers TC, Duane TM, Aboutanos MB, et al. DVT surveillance program in the ICU: analysis of cost-effectiveness. PLoS One. 2014;9(9):e106793.

4. Duarte PAD, Leichtweis GE, Andriolo L, Delevatti YA, Jorge AC, Fumagalli AC, Santos LC, Miura CK, Saito SK. Factors associated with the incidence and severity of new-onset atrial fibrillation in adult critically ill patients. Crit Care Res Pract. 2017:2017:8046240.

5. Klein Klouwenberg PM, Frencken JF, Kuipers S, Ong DS, Peelen LM, van Vught LA, Schultz MJ, van der Poll T, Bonten MJ, Cremer OL, et al. Incidence, predictors, and outcomes of new-onset atrial fibrillation in critically ill patients with Sepsis. A cohort study. Am J Respir Crit Care Med. 2017;195(2): 205-11.

6. Moss TJ, Calland JF, Enfield KB, Gomez-Manjarres DC, Ruminski C, DiMarco JP, Lake DE, Moorman JR. New-onset atrial fibrillation in the critically ill. Crit Care Med. 2017:45(5):790-7.

7. Sibley S, Muscedere J. New-onset atrial fibrillation in critically ill patients. Can Respir J. 2015;22(3):179-82.

8. Rali P, Gangemi A, Moores A, Mohrien K, Moores L. Direct-acting Oral anticoagulants in critically ill patients. Chest. 2019;156(3):604-18.

9. Tapson VF, Shirvanian S. Anticoagulation. In: Oropello JM, Pastores SM Kvetan V, editors. Critical Care. New York, NY: McGraw-Hill Education; 2017.

10. Hyers TM. Management of venous thromboembolism: past, present, and future. Arch Intern Med. 2003;163(7):759-68. 
11. Hylek EM, Regan S, Henault LE, Gardner M, Chan AT, Singer DE, Barry MJ. Challenges to the effective use of unfractionated heparin in the hospitalized management of acute thrombosis. Arch Intern Med. 2003;163(5):621-7.

12. Smith SB, Geske JB, Maguire JM, Zane NA, Carter RE, Morgenthaler TI. Early anticoagulation is associated with reduced mortality for acute pulmonary embolism. Chest. 2010;137(6):1382-90.

13. Aarab R, van Es J, de Pont AC, Vroom MB, Middeldorp S. Monitoring of unfractionated heparin in critically ill patients. Neth J Med. 2013;71(9):46671.

14. Bagshaw SM, George C, Dinu I, Bellomo R. A multi-Centre evaluation of the RIFLE criteria for early acute kidney injury in critically ill patients. Nephrol Dial Transplant. 2008;23(4):1203-10.

15. Khwaja A. KDIGO clinical practice guidelines for acute kidney injury. Nephron Clin Pract. 2012;120(4):c179-84.

16. Ostermann M, Chang RW. Acute kidney injury in the intensive care unit according to RIFLE. Crit Care Med. 2007;35(8):1837-43 quiz 1852.

17. Ricci Z, Cruz D, Ronco C. The RIFLE criteria and mortality in acute kidney injury: a systematic review. Kidney Int. 2008;73(5):538-46.

18. Thakar CV, Christianson A, Freyberg R, Almenoff $P$, Render ML. Incidence and outcomes of acute kidney injury in intensive care units: a veterans administration study. Crit Care Med. 2009;37(9):2552-8.

19. Hoste EA, Bagshaw SM, Bellomo R, Cely CM, Colman R, Cruz DN, Edipidis K, Forni LG, Gomersall CD, Govil D, et al. Epidemiology of acute kidney injury in critically ill patients: the multinational AKI-EPI study. Intensive Care Med. 2015:41(8):1411-23.

20. Bagshaw SM, Uchino S, Bellomo R, Morimatsu H, Morgera S, Schetz M, Tan I, Bouman C, Macedo E, Gibney N, et al. Septic acute kidney injury in critically ill patients: clinical characteristics and outcomes. Clin J Am Soc Nephrol. 2007;2(3):431-9

21. Uchino S, Kellum JA, Bellomo R, Doig GS, Morimatsu H, Morgera S, Schetz M, Tan I, Bouman C, Macedo E, et al. Acute renal failure in critically ill patients: a multinational, multicenter study. JAMA. 2005;294(7):813-8.

22. Brophy DF, Carr ME Jr, Martin EJ, Venitz J, Gehr TW. The pharmacokinetics of enoxaparin do not correlate with its pharmacodynamic effect in patients receiving dialysis therapies. J Clin Pharmacol. 2006;46(8):887-94.

23. Tsai TT, Maddox TM, Roe MT, Dai D, Alexander KP, Ho PM, Messenger JC, Nallamothu BK, Peterson ED, Rumsfeld JS, et al. Contraindicated medication use in dialysis patients undergoing percutaneous coronary intervention. JAMA. 2009;302(22):2458-64.

24. Kearon C, Akl EA, Ornelas J, Blaivas A, Jimenez D, Bounameaux H, Huisman M, King CS, Morris TA, Sood N, et al. Antithrombotic therapy for VTE disease: CHEST quideline and expert panel report. Chest. 2016;149(2):315-52.

25. Shaikh SA, Regal RE. Dosing of enoxaparin in renal impairment. P T. 2017; 42(4):245-9.

26. Agnelli G, Buller HR, Cohen A, Curto M, Gallus AS, Johnson M, Masiukiewicz U, Pak R, Thompson J, Raskob GE, et al. Oral apixaban for the treatment of acute venous thromboembolism. N Engl J Med. 2013;369(9):799-808.

27. Granger CB, Alexander JH, McMurray JJ, Lopes RD, Hylek EM, Hanna M, AlKhalidi HR, Ansell J, Atar D, Avezum A, et al. Apixaban versus warfarin in patients with atrial fibrillation. N Engl J Med. 2011;365(11):981-92.

28. Levy JH, Faraoni D, Spring $J$, Douketis JD, Samama CM. Managing new oral anticoagulants in the perioperative and intensive care unit setting. Anesthesiology. 2013;118(6):1466-74.

29. Garg VP, Halperin JL. Novel antiplatelet and anticoagulant agents in the cardiac care unit. Cardiol Clin. 2013:31(4):533-44 viii.

30. Johnson SA, Yarbrough PM, Rose RS, Lanspa MJ. Prescribing patterns of target-specific oral anticoagulants: an academic hospital perspective. Blood Coagul Fibrinolysis. 2015;26(7):767-71.

31. ELIQUIS (apixaban) package insert. Princeton, NJ and New York, NY: BristolMyers Squibb Company and Pfizer Inc.; Revised 2019 Nov. https://www. accessdata.fda.gov/drugsatfda_docs/label/2012/202155s000lbl.pdf. Accessed 8 July 2020

32. Kimachi M, Furukawa TA, Kimachi K, Goto Y, Fukuma S, Fukuhara S. Direct oral anticoagulants versus warfarin for preventing stroke and systemic embolic events among atrial fibrillation patients with chronic kidney disease. Cochrane Database Syst Rev. 2017:11:CD011373.

33. Mavrakanas TA, Samer CF, Nessim SJ, Frisch G, Lipman ML. Apixaban pharmacokinetics at steady state in hemodialysis patients. J Am Soc Nephrol. 2017;28(7):2241-8.

34. Siontis KC, Zhang X, Eckard A, Bhave N, Schaubel DE, He K, Tilea A, Stack AG, Balkrishnan R, Yao X, et al. Outcomes associated with Apixaban use in patients with end-stage kidney disease and atrial fibrillation in the United States. Circulation. 2018;138(15):1519-29.

35. Wang X, Tirucherai G, Marbury TC, Wang J, Chang M, Zhang D, Song Y, Pursley J, Boyd RA, Frost C. Pharmacokinetics, pharmacodynamics, and safety of apixaban in subjects with end-stage renal disease on hemodialysis. J Clin Pharmacol. 2016;56(5):628-36.

36. U.S. Department of Health and Human Services. Food and Drug Administration: Center for Drug Evaluation and Research. Guidance for Industry: Pharmacokinetics in Patients with Impaired Renal Function - Study Design, Data Analysis, and Impact on Dosing. Available at https://www.fda. gov/media/78573/download. Accessed 20 October 2020.

37. Beumier M, Roberts JA, Kabtouri H, Hites M, Cotton F, Wolff F, Lipman J, Jacobs F, Vincent JL, Taccone FS. A new regimen for continuous infusion of vancomycin during continuous renal replacement therapy. J Antimicrob Chemother. 2013:68(12):2859-65.

38. Roberts JA, Udy AA, Bulitta JB, Stuart J, Jarrett P, Starr T, Lassig-Smith M, Roberts NA, Dunlop R, Hayashi Y, et al. Doripenem population pharmacokinetics and dosing requirements for critically ill patients receiving continuous venovenous haemodiafiltration. J Antimicrob Chemother. 2014; 69(9):2508-16

39. Roberts DM, Liu X, Roberts JA, Nair P, Cole L, Roberts MS, Lipman J, Bellomo $R$. A multicenter study on the effect of continuous hemodiafiltration intensity on antibiotic pharmacokinetics. Critical Care (London, England). 2015;19:84.

40. Jamal JA, Udy AA, Wallis SC, Ranganathan D, McWhinney BC, Ungerer JP, Lipman J, Roberts JA. Can we use an ex vivo continuous hemofiltration model to describe the adsorption and elimination of meropenem and piperacillin? Int J Artif Organs. 2015;38(8):419-24.

41. Roger C, Wallis SC, Muller L, Saissi G, Lipman J, Bruggemann RJ, Lefrant JY, Roberts JA. Caspofungin population pharmacokinetics in critically ill patients undergoing continuous Veno-venous Haemofiltration or Haemodiafiltration. Clin Pharmacokinet. 2017:56(9):1057-68.

42. Churchwell MD. Use of an in vitro model of renal replacement therapy systems to estimate extracorporeal drug removal. J Clin Pharmacol. 2012; 52(1 Suppl):35s-44s

43. Bulitta JB, Hope WW, Eakin AE, Guina T, Tam VH, Louie A, Drusano GL Hoover JL. Generating Robust and Informative Nonclinical In Vitro and In Vivo Bacterial Infection Model Efficacy Data To Support Translation to Humans. Antimicrob Agents Chemother. 2019;63(5):e02307-18.

44. PRISMAFLEX System M60/M100/M150 Hemofilter Sets [https://econnect. baxter.com/assets/downloads/products_expertise/renal_therapies/ PRISMAFLEX_System_M60_M100_M150.pdf]. Accessed 8 July 2020.

45. PRISMAFLEX System HF1000/HF1400 Hemofilter Sets [https://econnect. baxter.com/assets/downloads/products_expertise/renal_therapies/ Prismaflex_HF_Spec_Sheet.pdf]. Accessed 8 July 2020.

46. Charlson F, Degenhardt L, McLaren J, Hall W, Lynskey M. A systematic review of research examining benzodiazepine-related mortality. Pharmacoepidemiol Drug Saf. 2009;18(2):93-103.

47. Frost C, Wang J, Nepal S, Schuster A, Barrett YC, Mosqueda-Garcia R, Reeves RA, LaCreta F. Apixaban, an oral, direct factor Xa inhibitor: single dose safety, pharmacokinetics, pharmacodynamics and food effect in healthy subjects. Br J Clin Pharmacol. 2013;75(2):476-87.

48. Pursley J, Shen JX, Schuster A, Dang OT, Lehman J, Buonarati MH, Song Y, Aubry AF, Arnold ME. LC-MS/MS determination of apixaban (BMS-562247) and its major metabolite in human plasma: an application of polarity switching and monolithic HPLC column. Bioanalysis. 2014;6(15):2071-82.

49. Churchwell MD, Pasko DA, Mueller BA. Daptomycin clearance during modeled continuous renal replacement therapy. Blood Purif. 2006:24(5-6):548-54.

50. Golper TA, Wedel SK, Kaplan AA, Saad AM, Donta ST, Paganini EP. Drug removal during continuous arteriovenous hemofiltration: theory and clinical observations. Int J Artif Organs. 1985;8(6):307-12.

51. Schetz M. Drug dosing in continuous renal replacement therapy: general rules. Curr Opin Crit Care. 2007;13(6):645-51.

52. Choi G, Gomersall CD, Tian Q, Joynt GM, Freebairn R, Lipman J. Principles of antibacterial dosing in continuous renal replacement therapy. Crit Care Med. 2009:37(7):2268-82

53. Sime FB, Pandey S, Karamujic N, Parker S, Alexander E, Loutit J, Durso S, Griffith D, Lipman J, Wallis SC, et al. Ex Vivo Characterization of Effects of Renal Replacement Therapy Modalities and Settings on Pharmacokinetics of Meropenem and Vaborbactam. Antimicrob Agents Chemother. 2018;62(10): e01306-18. 
54. Frost C, Nepal S, Wang J, Schuster A, Byon W, Boyd RA, Yu Z, Shenker A, Barrett YC, Mosqueda-Garcia R, et al. Safety, pharmacokinetics and pharmacodynamics of multiple oral doses of apixaban, a factor Xa inhibitor, in healthy subjects. Br J Clin Pharmacol. 2013;76(5):776-86.

55. Byon W, Sweeney K, Frost C, Boyd RA. Population pharmacokinetics, pharmacodynamics, and exploratory exposure-response analyses of Apixaban in subjects treated for venous thromboembolism. CPT Pharmacometrics Syst Pharmacol. 2017;6(5):340-9.

56. Byon W, Garonzik S, Boyd RA, Frost CE. Apixaban: a clinical pharmacokinetic and Pharmacodynamic review. Clin Pharmacokinet. 2019;58(10):1265-79.

57. Troyanov S, Cardinal J, Geadah D, Parent D, Courteau S, Caron S, Leblanc M. Solute clearances during continuous venovenous haemofiltration at various ultrafiltration flow rates using Multiflow-100 and HF1000 filters. Nephrol Dial Transplant. 2003;18(5):961-6.

58. He K, Luettgen JM, Zhang D, He B, Grace JE, Xin B, Pinto DJP, Wong PC, Knabb RM, Lam PYS, et al. Preclinical pharmacokinetics and pharmacodynamics of apixaban, a potent and selective factor Xa inhibitor. Eur J Drug Metab Pharmacokinet. 2011;36(3):129-39.

59. Bunnell K, Wenzler E, Rodvold K. 1362: evaluation of clearance equations in continuous renal replacement therapy with an in vitro model. Crit Care Med. 2018:46(1):664

60. Vilay AM, Shah KH, Churchwell MD, Patel JH, DePestel DD, Mueller BA. Modeled Dalbavancin Transmembrane clearance during intermittent and continuous renal replacement therapies. Blood Purif. 2010;30(1):37-43.

61. Westermann H, Choi TN, Briggs WM, Charlson ME, Mancuso CA. Obesity and exercise habits of asthmatic patients. Ann Allergy Asthma Immunol. 2008;101(5):488-94.

62. Boutin-Foster C, Charlson ME. Do recent life events and social support explain gender differences in depressive symptoms in patients who had percutaneous transluminal coronary angioplasty? J Women's Health (Larchmt). 2007;16(1):114-23.

63. Neuman HB, Charlson ME, Temple LK. Is there a role for decision aids in cancer-related decisions? Crit Rev Oncol Hematol. 2007;62(3):240-50.

64. Groetzinger LM, Miller TJ, Rivosecchi RM, Smith RE, Gladwin MT, RiveraLebron BN. Apixaban or rivaroxaban versus warfarin for treatment of submassive pulmonary embolism after catheter-directed thrombolysis. Clin Appl Thromb Hemost. 2018;24(6):908-13.

65. Chaijamorn W, Shaw AR, Lewis SJ, Mueller BA. Ex vivo Ceftolozane/ Tazobactam clearance during continuous renal replacement therapy. Blood Purif. 2017:44(1):16-23.

66. Lewis SJ, Switaj LA, Mueller BA. Tedizolid adsorption and Transmembrane clearance during in vitro continuous renal replacement therapy. Blood Purif. 2015;40(1):66-71.

67. Kesner JM, Yardman-Frank JM, Mercier RC, Wong CS, Walker SE, Argyres DP, Vilay AM. Trimethoprim and sulfamethoxazole transmembrane clearance during modeled continuous renal replacement therapy. Blood Purif. 2014; 38(3-4):195-202

68. Jang SM, Hough $G$, Mueller BA. Ex vivo Rezafungin adsorption and clearance during continuous renal replacement therapy. Blood Purif. 2018; 46(3):214-9.

69. Akers KS, Rowan MP, Niece KL, Stewart IJ, Mende K, Cota JM, Murray CK, Chung KK. Colistin pharmacokinetics in burn patients during continuous venovenous hemofiltration. Antimicrob Agents Chemother. 2015;59(1):46-52

70. Uchino S, Cole L, Morimatsu H, Goldsmith D, Bellomo R. Clearance of vancomycin during high-volume haemofiltration: impact of pre-dilution. Intensive Care Med. 2002;28(11):1664-7.

71. Janssen PK, Foudraine NA, Burgers DM, Neef K, le Noble JL. Population pharmacokinetics of cefuroxime in critically ill patients receiving continuous Venovenous hemofiltration with regional citrate anticoagulation and a phosphate-containing replacement fluid. Ther Drug Monit. 2016;38(6):699-705.

72. Tegeder I, Bremer F, Oelkers R, Schobel H, Schüttler J, Brune K, Geisslinger G. Pharmacokinetics of imipenem-cilastatin in critically ill patients undergoing continuous venovenous hemofiltration. Antimicrob Agents Chemother. 1997;41(12):2640-5.

73. Boucher BA, Hudson JQ, Hill DM, Swanson JM, Wood GC, Laizure SC, ArnoldRoss A, Hu ZY, Hickerson WL. Pharmacokinetics of Imipenem/Cilastatin burn intensive care unit patients undergoing high-dose continuous Venovenous hemofiltration. Pharmacotherapy. 2016;36(12):1229-37.

74. Kiser $T H$, Fish $D N$, Aquilante $C L$, Rower JE, Wempe MF, MacLaren $R$, Teitelbaum I. Evaluation of sulfobutylether- $\beta$-cyclodextrin (SBECD) accumulation and voriconazole pharmacokinetics in critically ill patients undergoing continuous renal replacement therapy. Crit Care. 2015;19(1):32.

75. Li AM, Gomersall CD, Choi G, Tian Q, Joynt GM, Lipman J. A systematic review of antibiotic dosing regimens for septic patients receiving continuous renal replacement therapy: do current studies supply sufficient data? J Antimicrob Chemother. 2009;64(5):929-37.

76. Hoff BM, Maker JH, Dager WE, Heintz BH. Antibiotic dosing for critically ill adult patients receiving intermittent hemodialysis, prolonged intermittent renal replacement therapy, and continuous renal replacement therapy: an update. Ann Pharmacother. 2020;54(1):43-55.

77. Charlson ME, Peterson JC, Krieger KH, Hartman GS, Hollenberg JP, Briggs WM, Segal AZ, Parikh M, Thomas SJ, Donahue RG, et al. Improvement of outcomes after coronary artery bypass II: a randomized trial comparing intraoperative high versus customized mean arterial pressure. J Card Surg. 2007:22(6):465-72

78. WTPW, Guerra Valero Y, Choi GYS, Ordóñez Mejia JL, Wallis SC, Joynt GM, Lipman J, Gomersall CD, Roberts JA. In-vitro adsorption and sieving coefficient of ticarcillin-clavulanate during continuous haemofiltration. Int J Antimicrob Agents. 2019;54(2):261-4.

79. Roehr AC, Frey OR, Koeberer A, Fuchs T, Roberts JA, Brinkmann A. Antiinfective drugs during continuous hemodialysis - using the bench to learn what to do at the bedside. Int J Artificial Organs. 2015;38(1):17-22.

80. Onichimowski D, Ziółkowski H, Nosek K, Jaroszewski J, Rypulak E, Czuczwar M. Comparison of adsorption of selected antibiotics on the filters in continuous renal replacement therapy circuits: in vitro studies. J Artificial Organs. 2020;23(2):163-70.

81. Tian Q, Gomersall CD, Ip M, Tan PE, Joynt GM, Choi GYS. Adsorption of Amikacin, a significant mechanism of elimination by hemofiltration. Antimicrob Agents Chemother. 2008;52(3):1009-13.

82. Quale JM, O'Halloran JJ, DeVincenzo N, Barth RH. Removal of vancomycin by high-flux hemodialysis membranes. Antimicrob Agents Chemother. 1992; 36(7):1424-6.

83. Choi G, Gomersall CD, Lipman J, Wong A, Joynt GM, Leung P, Ramsay SJ, Ho OM. The effect of adsorption, filter material and point of dilution on antibiotic elimination by haemofiltration an in vitro study of levofloxacin. Int J Antimicrob Agents. 2004;24(5):468-72.

84. Vilay AM, Churchwell MD, Mueller BA. Clinical review: Drug metabolism and nonrenal clearance in acute kidney injury. Critical Care (London, England). 2008;12(6):235.

85. Wu X, Clancy CJ, Rivosecchi RM, Zhao W, Shields RK, Marini RV, Venkataramanan R, Nguyen MH. Pharmacokinetics of intravenous Isavuconazole in solid-organ transplant recipients. Antimicrob Agents Chemother. 2018;62(12):e01643-18.

86. Wenzler E, Biagi M, Tan X, Butler DA. Reply to Baud and Houzé, "Should In Vitro and In Vivo Studies on Antimicrobial Agents during Continuous Renal Replacement Therapy Comply with General Principles of Pharmacokinetics?". Antimicrob Agents Chemother. 2020;64(6):e00388-20.

87. Ricci Z, Ronco C, D'Amico G, De Felice R, Rossi S, Bolgan I, Bonello M, Zamperetti N, Petras D, Salvatori G, et al. Practice patterns in the management of acute renal failure in the critically ill patient: an international survey. Nephrol Dial Transplant. 2006;21(3):690-6.

\section{Publisher's Note}

Springer Nature remains neutral with regard to jurisdictional claims in published maps and institutional affiliations.

Ready to submit your research? Choose BMC and benefit from:

- fast, convenient online submission

- thorough peer review by experienced researchers in your field

- rapid publication on acceptance

- support for research data, including large and complex data types

- gold Open Access which fosters wider collaboration and increased citations

- maximum visibility for your research: over $100 \mathrm{M}$ website views per year

At $\mathrm{BMC}$, research is always in progress.

Learn more biomedcentral.com/submission 